\title{
VISUALISASI HEWAN PADA RELIEF RAMAYANA CANDI PRAMBANAN
}

\author{
Henny Hidajat ${ }^{{ }^{*}}$ \\ ${ }^{1}$ Program Studi Desain Komunikasi Visual, Universitas Bunda Mulia, Jl. Lodan Raya No. 2 Ancol, \\ Jakarta Utara 14430, Indonesia \\ Diterima: /Disetujui:
}

\begin{abstract}
ABSTRAK
Hewan-hewan yang tergambar pada Relief Ramayana di Candi Prambanan tidak hanya memiliki fungsi sebagai elemen dekoratif tetapi juga memiliki peran sebagai pelengkap alur cerita Ramayana serta memiliki makna simbolis. Artikel ini disusun berdasarkan penelitian untuk mengungkapkan deskripsi visual dari keragaman hewan yang tergambar pada Relief Ramayana di Candi Prambanan, Jawa Tengah untuk meneliti gaya visual, karakteristik, atribut, serta peranan hewan-hewan tersebut dalam mendukung alur cerita Ramayana. Berdasarkan dokumentasi lapangan dari karakter hewan-hewan yang tergambar pada relief candi dan referensi sejarah, literatur Ramayana serta literature lainnya, maka diharapkan bahwa visualisasi dari hewan-hewan tersebut seperti bentuk fisik, gaya, peran serta maknanya dapat dianalisis.

Dengan demikian suatu kesimpulan dapat disimpulkan sebagai suatu referensi visual bagi penelitian selanjutnya maupun proyek desain ataupun seni kreatif lainnya, terutama yang dibangun berdasarkan inspirasi kebudayaan dan tradisi.
\end{abstract}

Kata Kunci: relief candi, Prambanan, hewan, karakteristik visual

\begin{abstract}
The animals as described in Ramayana Relief of Prambanan Temple are not only functioned as decorative element, but also had other role to complete storyline of Ramayana and symbolic meaning. The article is created based on a research to explain about visual description of the variety of the animals described in Ramayana Relief of Prambanan Temple in Central Java, to reveal their visual style, characteristics, attributes, and their roles to support Ramayana storyline. Based on field documentation of the animals characters described in the relief and other references about history, Ramayana literature, and others, the visualization of the animals, such as physical shape, style, roles and their meaning can be analyzed
\end{abstract}

Therefore a result can be concluded as a visual reference for the next research and for creative art or design projects, especially which will be developed based on culture and tradition inspiration.

Keyword: temple relief, Prambanan, animals, visual characteristics

\section{PENDAHULUAN}

Prambanan merupakan candi Hindu yang dibangun pada masa pemerintahan Raja Pikatan pada abad ke-9. Candi Prambanan memiliki tiga candi utama untuk menghormati Trimurti, yaitu Dewa
Siwa, Dewa Brahma serta Dewa Wisnu. Pada Candi Siwa terdapat Relief Ramayana yang bersambung ke Candi Brahma.

*email: hhidajat@bundamulia.ac.id 


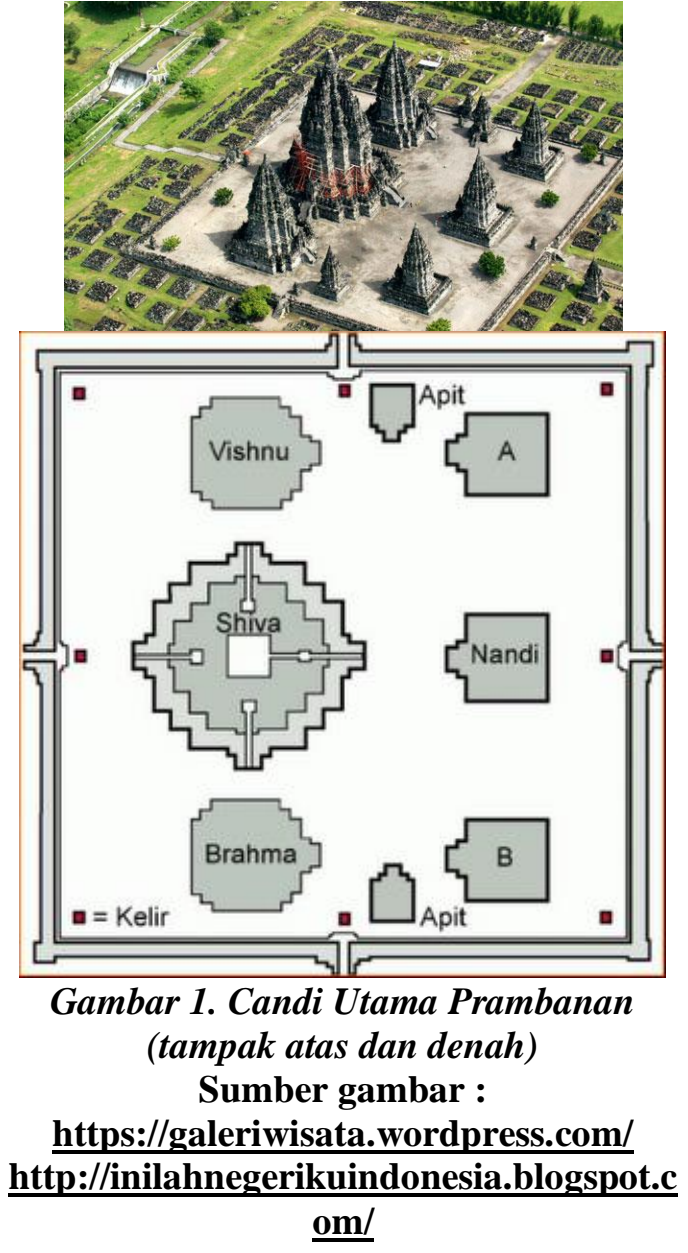

Relief cerita Ramayana, memberikan gambaran tentang jalannya cerita Ramayana, yaitu Sinta yang diculik oleh raksasa Rahwana lalu berusaha untuk dibebaskan oleh Sri Rama dengan dibantu oleh sekutu-sekutunya. Namun tidak hanya itu, relief juga menggambarkan hal-hal pada masanya yang dapat memberikan gambaran pada masa kini tentang pakaian, rumah, benda-benda, tanaman serta hewan pada masanya, walaupun penggambaran pada relief juga mengikutsertakan stilasi.

Melalui relief Ramayana pada Candi Prambanan dapat kita pelajari keragaman satwa yang saat itu berkembang di Jawa, terutama Jawa Tengah serta bagaimana gaya visualisasinya. Dalam cerita Ramayana, satwa yang tampil dalam cerita seringkali bukan hanya satwa biasa, tetapi juga melibatkan simbolisasi dan tokoh-tokoh mitologis dalam agama Hindu yang penampilannya merupakan binatang, misalnya tokoh Hanoman ataupun burung Jatayu, yang memiliki peran penting dalam cerita.

Kajian yang dibuat berdasarkan penelitian mengenai keragaman satwa menjadi penting dan menarik karena di masa kini dapat diketahui bagaimana penggambaran ragam satwa yang ada pada masa itu, termasuk hewan-hewan yang berperan dalam mitologi. Kajian mengenai penggambaran tersebut dapat menjadi suatu referensi visual baik bagi penelitian selanjutnya, maupun bagi dasar pemikiran untuk mengembangkan ilustrasi, komik, animasi ataupun pengembangan tokoh karakter yang berperan dalam perkembangan desain maupun budaya populer masa kini, terutama yang mengambil inspirasi dari budaya tradisi. Dengan demikian diharapkan dapat tercipta pelestarian tradisi budaya dan juga perkembangan industri kreatif di Indonesia. Terlebih lagi, di masa kini penciptaan karya desain ilustrasi, komik, animasi maupun pengembangan tokoh karakter menjadi industri yang semakin pesat, baik di dunia internasional maupun di Indonesia sendiri. Inspirasi cerita yang merupakan warisan budaya banyak diangkat sebagai upaya pelestarian tradisi nusantara serta memperkenalkan tradisi kepada generasi muda. Untuk itu dibutuhkan suatu referensi visual yang berkaitan dengan sumber asli dari gaya visual dan penggambaran yang sesuai tradisi, yaitu melalui artefak peninggalan budaya, dalam hal ini adalah Relief Ramayana pada Candi Prambanan. Sekalipun dalam dunia kreatif selalu terdapat gaya-gaya dengan pendekatan artistik yang lebih populer dan modern, namun tetap dibutuhkan suatu panduan referensi visual dari sumbernya. Dengan demikian kajian ini secara tidak langsung diharapkan dapat menyuburkan upaya pelestarian tradisi budaya nusantara melalui pemahaman nilai-nilainya.

\section{Metodologi}

Pengumpulan data dalam kajian ini dilakukan dengan studi literatur, berkaitan dengan sejarah dan cerita Ramayana maupun relief Prambanan. Proses pengumpulan data juga dilakukan melalui 
pengamatan dan dokumentasi terhadap Relief Candi Prambanan, terutama Candi Siwa dan Candi Brahma yang relief-nya menggambarkan cerita Ramayana.

Penelitian ini bersifat kualitatif deskriptif yang menggambarkan fakta secara sistematis sifat dari suatu objek. Dalam penelitian ini dilakukan penelusuran data pada relief Ramayana Candi Prambanan secara faktual. Data visualisasi cerita yang dikumpulkan lalu dianalisis dengan proses identifikasi, kategorisasi dan pemaknaan sehingga menimbulkan pemahaman yang baru, seperti hewan apa saja yang dapat ditemukan, bagaimana ciriciri, atribut dan peranannya dalam cerita serta simbol-simbol dan makna yang diwakilinya. Analisis data dilakukan secara induktif, yaitu bahwa data yang telah terkumpul disusun dan dianalisis bersama dengan proses pengumpulan datanya (Sutopo, 2006:41). Dalam penelitian ini hasil penelusuran referensi dan lapangan yang dikumpulkan lalu disusun dan dianalisis bersama.

Kajian ini menerapkan pendekatan ikonografi dalam menganalisis tokoh dan visualisasi yang terpahat pada relief Ramayana di Candi Prambanan. Menurut Erwin Panofsky (Panofsky, 1993 : 3 dalam Leeuwen), ikonografi merupakan kajian yang memperhatikan konfigurasi dari gambar pada suatu karya untuk mengetahui makna yang tersembunyi. Ikonografi biasanya dipahami sebagai kajian tentang tanda yang memiliki referensi, yang objek kajiannya mencakup berbagai disiplin pemikiran.

Ikonografi memiliki pokok kajian yang berkaitan dengan sisi manusia (subject matter) atau makna dari suatu karya seni sebagai sesuatu yang terkadang bertolak belakang dengan bentuk karya tersebut, yaitu sisi formalisnya (Panofsky, 1993 : 3 dalam Leeuwen).

Tiga lapisan makna piktorial pada pendekatan ikonografi (Van Leeuwen, 2001: 100):

1. Makna representasional merupakan pemaknaan terhadap tampilkan yang memanfaatkan konvensi stilasi dan transformasi teknis yang terlibat dalam representasi tersebut, dimana pengetahuan tentang konteks dari gambar dibutuhkan untuk memaknainya

2. Simbolisme ikonografikal yang tidak hanya berusaha memaknai orang, tempat ataupun benda dalam gambar, tetapi juga ide dan konsep dibaliknya,

3. Simbolisme ikonologikal yang dapat dikatakan merupakan makna ideologis.

Untuk mengkaji makna-makna tersebut Panosfky menjelaskan proses menginterpretasi obyek seni dan gambar dapat melalui tiga tahapan berikut :

\section{Tahap Preiconographical}

Tahapan untuk mengidentifikasi melalui hal-hal yang sudah dikenal dan natural. Merupakan pemahaman secara faktual dan ekspresional. yang didasarkan atas pengalaman setiap individu terhadap suatu objek gambar, yang dilakukan dengan mengamati dan mengindentifikasi unsur artistik dari objek gambar, yaitu konfigurasi tertentu dari garis dan warna, atau bentuk dan material yang merepresentasikan objek keseharian tertentu, hubungan-hubungan yang terjadi pada objek dan identifikasi kualitas ekspresional tertentu dengan melakukan pengamatan pose atau gesture dari objek.

Pada tahap ini penelitian yang dilakukan berada pada tahap eskipsi ciri-ciri visual yang tampak pada satwa-satwa yang ada pada relief Ramayana Candi Prambanan.

\section{Tahap Iconographical}

Merupakan tahapan untuk mengidentifikasi makna sekunder dengan melihat hubungan antara motif sebuah seni dengan tema, konsep atau makna yang lazim terhadap peristiwa yang diangkat oleh sebuah gambar. Motif-motif yang kemudian dikenali sebagai pembawa makna sekunder disebut sebagai image/citra/wujud.

Dalam penelitian tahapan ini dilakukan analisis rangkaian gambar dengan memperhatikan peristiwa yang berhubungan antara karya serta cerita Ramayana

\section{Tahap Interpretasi Ikonologi}

Pada tahapan ini makna dan peran yang paling hakiki dan mendasar dari satwa- 
satwa yang tergambar dalam relief Ramayana benar-benar perlu dipahami. Pemahaman mengenai makna intrinsik yang terdapat dalam para satwa ini dapat diperoleh dengan mengungkapkan karakteristik, atribut, pose dan gesture yang tergambar, serta kaitannya dengan cerita dan simbolisasi Hindu pada masa itu.

Dalam penelitian ini dilakukan interpretasi dengan mempertimbangkan visualisasi satwa-satwa tersebut, berkaitan dengan peran pada cerita maupun simbolsimbol dan makna lainnya yang terkandung dalam relief tersebut. Tahap Analisis dapat dilihat pada Bagan 1 berikut ini.

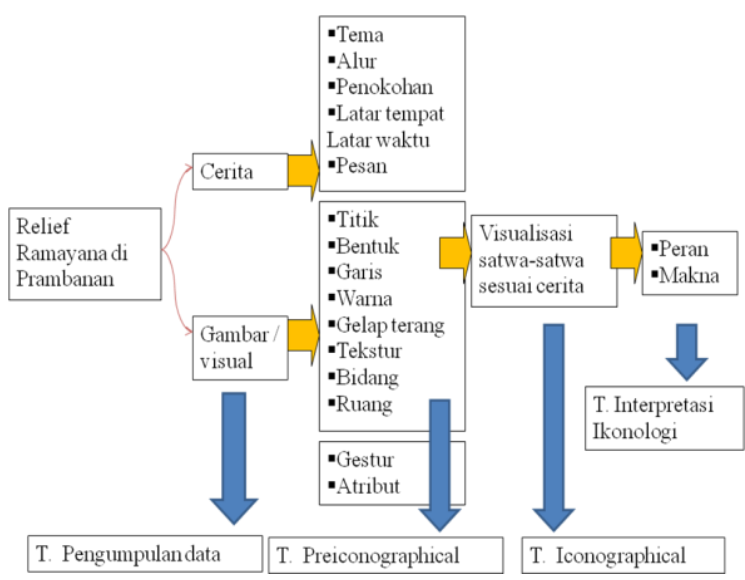

Bagan 1. Tahap Analisis

\section{Perkembangan Candi di Jawa Tengah}

Candi merupakan bangunan yang dikaitkan dengan fungsi peribadatan, seperti untuk tempat tinggal arca-arca dewa serta simbol-simbolnya, untuk menampung jemaat, untuk mengatur kegiatan ritual yang berlangsung di dalam lingkungan bangunan (Supratikno, 2011:211). Candi ada yang memiliki bilik, sebagai tempat penyimpanan arca dewa ataupun simbolsimbolnya dan ada yang tidak berbilik, baik yang memiliki arca dewa ataupun yang tanpa arca.

Menurut Supratikno (Supratikno, 2011:212), pada periode 770-850 M muncul bangunan-bangunan agama Budha yang pada umumnya berukuran besar, misalnya Borobudur, Kalasan dan Sewu, Mendut, Ngawen, Sajiwan, Lumbung, Banyunibo, Plaosan dan Sari. Pada umumnya candi-candi tersebut dibangun sebagai suatu kompleks yang terdiri dari sebuah bangunan induk dikelilingi oleh candi-candi kecil (perwara) yang merupakan miniatur candi induknya. Namun demikian pada periode ini terdapat pula bangunan Hindu memiliki karakteristik serupa bangunan monumental Budha tersebut, misalnya Candi Prambanan, yang juga dibangun dengan candi utama dikelilingi candi perwara-nya.

Berdasarkan sifat monumental tersebut dapat juga diperkirakan bahwa candi Prambanan digunakan untuk mewadahi jemaat dalam jumlah besar. Namun candi Prambanan memiliki pembatas halaman antara halaman yang berisi candi utama dengan candi-candi kecilnya. Setelah periode tersebut, yaitu sekitar sesudah abad ke-10, pembangunan candi besar di Jawa Tengah mulai berkurang. Sementara itu pembangunan candi baik candi Hindu maupun candi Budha di Jawa Timur masih terus berlangsung hingga abad ke-14.

\section{Relief Candi}

Relief dapat dibedakan berdasarkan tujuan penggambarannya menjadi relief cerita dan non-cerita (Supratikno, 2011:235). Relief cerita dimaksudkan untuk menyampaikan pesan secara naratif, sedangkan relief non-cerita lebih menekankan pada penyampaian pesan simboliknya. Relief biasanya dibuat berdasarkan suatu kitab tertentu, yang digunakan sebagai referensi untuk menyusun komposisinya. Pada dasarnya terdapat kaitan antara kitab sastra dengan relief candi yang keduanya bersumber pada ajaran agama..

Jenis relief non-cerita biasanya menampilkan dewa-dewa dan mahluk penghuni kahyangan, di samping satwa dan tumbuhan yang dikenal dalam kehidupan sehari-hari (Supratikno, 2011:228). Suatu kompleks candi seringkali memiliki kedua jenis relief sekaligus, yang bersifat saling melengkapi.

Relief candi diperkirakan memiliki fungsi-fungsi sebagai sarana penggambaran kosmos besar, yaitu penggambaran suasana dunia para dewa. Selain itu fungsi lainnya adalah sebagai sarana penggambaran 
pengalaman spiritual, yaitu memuat kisah perjalanan spiritual dalamupaya mencari kebenaran tertinggi, misalnya seperti yang terdapat pada relief Candi Borobudur. Fungsi lain dari relief candi adalah sebagai sarana untuk menghormati dewa, yang menggambarkan kisah tindak kepahlawanan dari para dewa, ataupun mahluk setengah dewa seperti misalnya relief Ramayana dan Kresnayana pada Candi Prambanan, yang dibuat dengan cerita tentang kepahlawanan Rama dan Kresna (Supratikno, 2011:232-233).

Ada pula pendapat bahwa relief juga digunakan sebagai sarana meditasi. Perkiraan ini dibuat berdasarkan adanya kesesuaian dengan aturan yang berlaku menurut sumber India. Disebutkan pula bahwa relief yang dibuat biasanya memiliki hubungan erat dengan arca pada biliknya. Relief pada dinding dimaksudkan untuk membimbing perhatian jemaat kepada dewa yang ada di dalam bilik. Dengan berjalan mengelilingi candi, mata jemaat diarahkan kepada relief-relief tersebut sehingga ketika memasuki bilik arca pikiran jemaat telah terpusat kepada dewa yang bersangkutan (Kramrich dalam Supratikno, 2011:234).

\section{Relief Ramayana Candi Prambanan}

Relief Ramayana terdapat pada dinding pagar Candi Siwa, sejumlah 12 panel yang menggambarkan 42 adegan. Panel dimulai dari pintu masuk ke kiri memutar searah jarum jam dan bersambung ke pagar dalam Candi Brahma, yang mencakup 30 adegan.

Menurut tujuan penggambarannya Relief Ramayana merupakan relief cerita, yaitu bertujuan untuk menyampaikan pesan secara naratif. Relief tersebut dibuat berdasarkan Kitab Ramayana karya Walmiki sebagai sumber. Selain itu, pada Candi Prambanan juga terdapat relief non cerita, yang lebih menekankan pada penyampaian pesan secara simbolik, misalnya relief tentang dewa-dewa dan mahluk penghuni kahyangan lainnya.

Relief candi berfugsi sebagai sarana untuk menghormati dewa. Relief Ramayana, sesuai dengan sumber ceritanya yaitu Kitab Ramayana, merupakan penghormatan terhadap tokoh Rama, titisan
Dewa Wisnu, yang harus melalui perjuangan panjang demi memperebutkan kembali istrinya, Shinta.

Relief Ramayana pada Candi Prambanan termasuk relief yang tergolong ukir dalam, artinya ukiran relief cenderung berdimensi sehingga menyerupai patung yang menempel ke dinding. Selain itu, penggambarannya cenderung realistik, sesuai dengan bentuk patung pada periode awal perkembangan agama Hindu di Nusantara yang masih mendapat pengaruh kuat dari India. Sifat ini berbeda dengan relief yang terdapat pada candi-candi Jawa Timur yang cenderung datar, dan memiliki penggambaran yang cenderung distilasi, yaitu disederhanakan.

\section{Sinopsis Cerita Ramayana}

Pada kompleks Candi Prambanan, relief Ramayana terbagi menjadi dua bagian, yaitu yang berada pada Candi Siwa dan berlanjut pada Candi Brahma. Sinopsis cerita adalah sebagai berikut.

Dewa Wisnu menitis pada Pangeran Rama dari Ayodhya, yang dimintai bantuan oleh Brahmana Wismamitra untuk mengatasi ulah Rahwana yang mengacau dunia. Rama bersama Laksmana melindungi Brahmana ketika bertapa. Ketika Raja Janaka mengadakan lomba memanah untuk memperebutkan Shinta, Rama berhasil memenangkannya dan menikah dengan Shinta.

Ketika kembali ke Ayodhya Rama akan dinobatkan sebagai raja. Sayangnya terjadi hasutan dari ibu tiri Rama, sehingga yang naik sebagai raja adalah saudara tirinya, yaitu Bharata. Sementara Rama dikucilkan ke hutan, disertai Shinta dan Laksmana. Namun ketika raja Ayodhya wafat, Bharata menolak menjadi raja dan menyusul Rama di hutan. Tetapi Rama memerintahkannya kembali dan menjadi raja.

Saat beristirahat Shinta diganggu raksasa, tetapi berhasil diusir Laksmana. Ada godaan terhadap Rama yang bersumber dari Rahwana sehingga luput menjaga Shinta, yaitu dengan godaan kijang emas yang disukai Shinta dan minta agar Rama dan Laksmana menangkapnya. 
Ketika Shinta sedang sendiri ia diculik Rahwana dan dibawa ke Alengka. Jatayu, yang menyaksikan hal itu dan melawan Rahwana untuk menolong Shinta, memberikan kabar kepada Rama dan Laksmana.

Dalam perjalanan mengejar Shinta, Rama didekati oleh Anoman yang minta bantuan agar Rama membantu Raja kera Sugriwa untuk melawan Subali, saudaranya. Rama berhasil membuat Sugriwa menang dan memperoleh bala bantuan dari pasukan kera dalam melawan Rahwana. Dalam perjalanan juga memperoleh bantuan dari pasukan ikan yang diketuai dewi Laut.

Shinta berhasil diselamatkan, namun karena sudah hamil dan Rama curiga, maka Rama membuang Shinta ke hutan. Shinta melahirkan bayi kembar Kusa dan Lava dan ditolong Mpu Walmiki. Beberapa tahun kemudian ketika Rama bertemu anak-anaknya, ia menyesal dan memberikan tahta kepada anak-anak Shinta.

\section{Visualisasi Relief Ramayana pada Candi Prambanan}

Sesuai dengan periode berdirinya Candi Prambanan, yaitu abad ke-9, candi ini termasuk candi yang dibangun pada masa awal perkembangan agama Hindu di Nusantara. Pada periode ini candi banyak dibangun di daerah Jawa Tengah. Dengan demikian relief candi cenderung bersifat ukir dalam dan realistik. Hal ini berbeda dengan sifat relief candi di Jawa Timur yang dibangun pada periode akhir Hindu, yaitu memiliki ukir datar dan tidak terlalu realistik.

Sesuai dengan sifat tersebut, maka relief hewan pada umumnya juga bersifat realistik dengan sedikit penyederhanaan, sehingga dapat dikatakan tidak mengalami banyak stilasi. Berikut pada Gambar 2 dan 3 adalah gambaran perbedaan visualisasi relief antara candi Jawa Tengah yang dibuat pada masa awal penyebaran agama Hindu di Jawa, yaitu Candi Prambanan dan candi Jawa Timur, yaitu Candi Panataran.

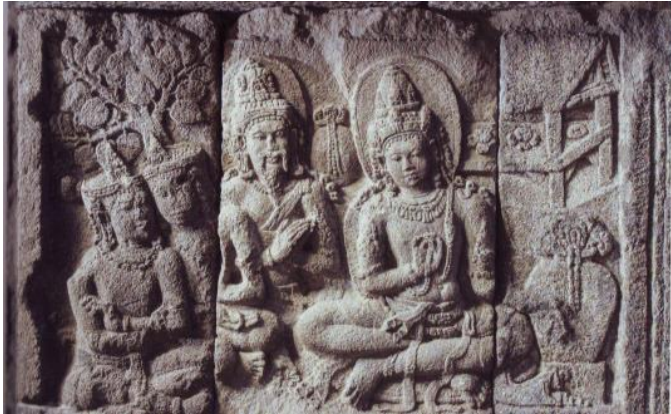

Gambar 2. Relief Candi Pramanan, Jawa Tengah

Relief Candi Prambanan di Jawa Tengah, dengan ukir timbul dan bentuk realistik.

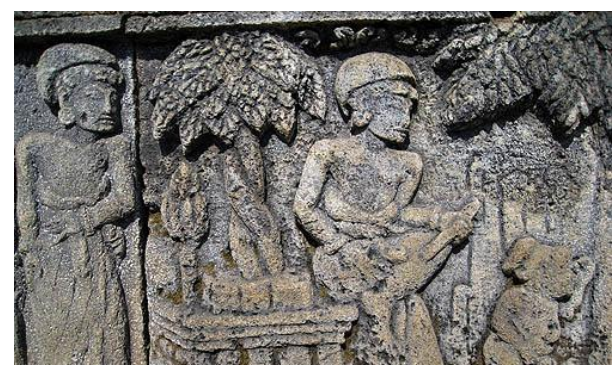

Gambar 3. Relief Candi Panataran Jawa Timur

Relief Candi Panataran di Jawa Timur, dengan ukir datar dan bentuk distilasi.

\section{Visualisasi Satwa pada Relief}

Beberapa satwa yang berhasil ditemukan pada Relief Ramayana Candi Prambanan antara lain : garuda, gajah, Jatayu, ikan, kuda, Hanoman (Kera Putih), kepiting, burung gagak, buaya, tupai, kera, ayam, trenggiling, kambing, kijang kencana

Berdasarkan satwa yang muncul dalam relief Ramayana Candi Siwa dan Candi Brahma maka dapat disimpulkan sebagai berikut :

Beberapa hewan merupakan tokoh yang berperan dalam cerita, seperti : Garuda, Jatayu, Kijang Kencana, Anoman, Subali \& Sugriwa. Garuda, Kijang Kencana dan Subali \& Sugriwa mengenakan perhiasan. Sementara Jatayu dan Hanoman tidak, tetapi Hanoman digambarkan dengan gestur sesuai cerita, seperti tergambar pada Gambar 4 berikut ini. 


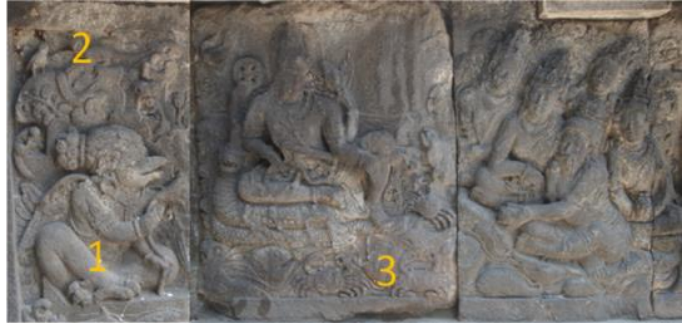

Gambar 4a. Tokoh Garuda (1), tupai (2) dan ikan (3) pada Relief adegan

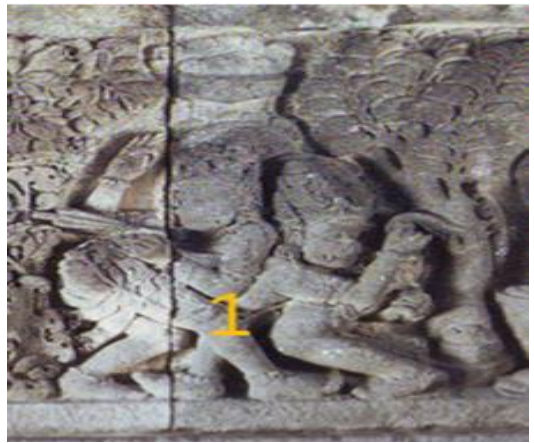

Gambar 4b. Relief Adegan 30, tampak tokoh Sugriwa (1)

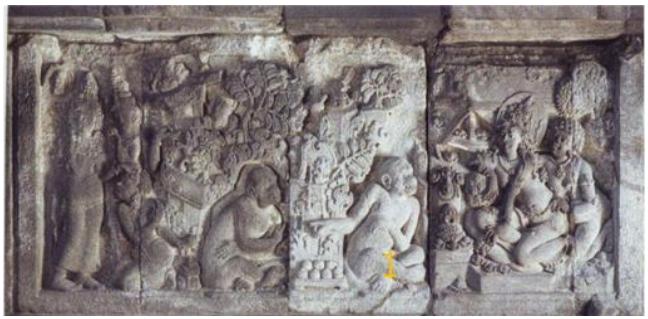

Gambar 4c. Relief Adegan 30, tampak tokoh Hanoman (1)

Beberapa hewan merupakan pembantu cerita, misalnya buaya, pasukan kera, pasukan ikan. Hal ini tampak pada Gambar 5, ketika pasukan kera anak buah Sugriwa melawan pasukan ikan anak buah Raja Laut, agar Rama dapat menyeberang menuju Kerajaan Alengka guna menyelamatkan Shinta.

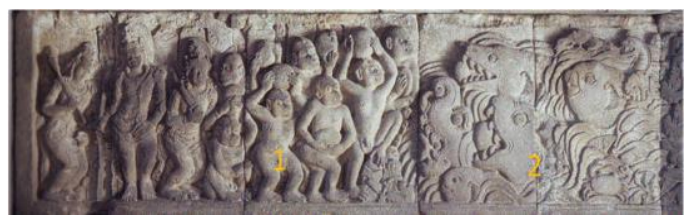

Gambar 5. Relief Adegan 41, dengan hewan kera (1) dan ikan (2)

Kuda dan gajah merupakan fasilitas kendaraan, baik sebagai tunggangan maupun penarik kereta. Gajah merupakan tunggangan kebesaran bagi bangsawan. Kedua hewan mengenakan perhiasan, kecuali kuda yang menarik kereta. Visualisasi kedua hewan itu dapat dilihat pada Gambar 6.

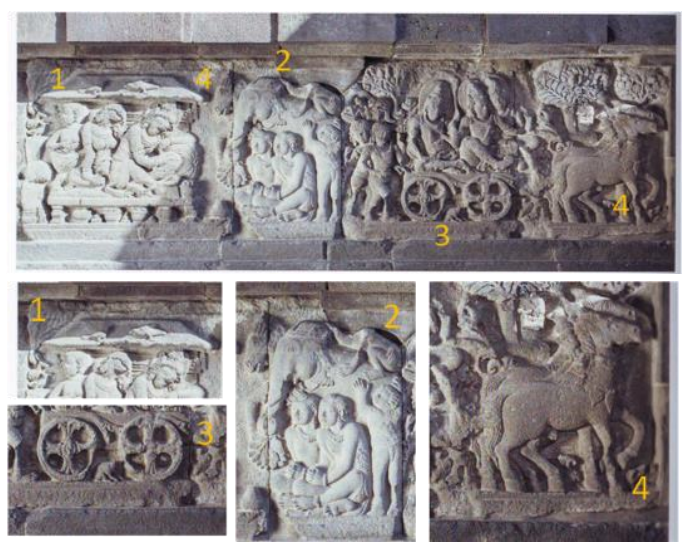

Gambar 6. Gambar 7. Relief dan detail Adegan 11-12, dengan hewan burung (1), gajah (2), tupai (3) dan kuda (4).

Beberapa hewan merupakan penanda latar, misalnya ikan dan kepiting yang menandai laut, trenggiling, tupai, burung, merupakan penanda hutan, ayam dan kambing penanda kediaman, seperti tergambar pada adegan relief pada Gambar 7, tampak trenggiling, tupai dan burung.

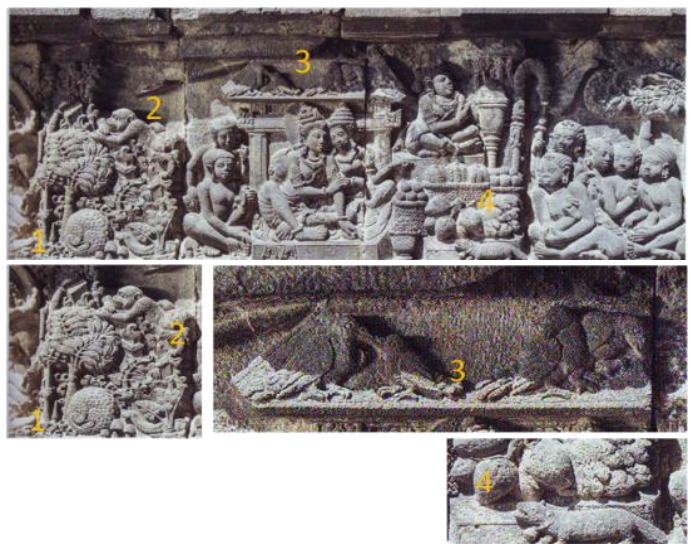

Gambar 7. Relief Adegan 9, dengan detail berupa hewan trenggiling (1), kera (2), burung (3) dan tupai (4)

\section{SIMPULAN}

Visualisasi hewan pada umunya bersifat realistik dengan sedikit 
penyederhanaan, sehingga dapat dikatakan tidak mengalami banyak stilasi

Sesuai dengan storyline cerita Ramayana dan kepercayaan agama Hindu yang mengenal mahluk-mahluk Mitologis, terdapat tokoh-tokoh yang dipersonifikasikan dalam rupa hewan, misalnya Garuda, Hanoman, raja kera Subali dan Sugriwa. Pada umumnya mereka digambarkan mengenakan busana ataupun atribut ataupun gesture seperti manusia.

Peran hewan lainnya yang kurang menonjol, tetapi memiliki kepribadian seperti manusia antara lain adalah pasukan kera dan ikan serta buaya. Peranan mereka adalah mendukung kepemimpinan ataupun arahan hewan-hewan yang menjadi tokoh cerita.

Sementara hewan lain merupakan penanda latar cerita, seperti ikan dan kepiting yang menandai laut, trenggiling, tupai, burung, merupakan penanda hutan, ayam dan kambing penanda kediaman.

\section{DAFTAR PUSTAKA}

Degroot, Veronique. 2013, Magical Prambanan, PT. Taman Wisata Candi Borobudur, Prambanan dan Ratu Boko, Yogyakarta.
Leeuwen, Theo van ; Jewitt, Carey 2001, Handbook of Visual Analysis, Sage, London.

Miksic, John (ed). 2009, Indonesian Heritage: Sejarah Awal ,Grolier International, Singapore.

------, 2002, Indonesian Heritage: Seni Arsitektur Edisi Bahasa Indonesia, Buku Antar Bangsa, Jakarta.

Mudhiuddin, Andi M. 2009, Borobudur, Prambanan dan Candi Lainnya, Kreasi Wacana, Yogyakarta.

Poesponegoro, Marwati D., Notosusanto, Nugroho. 2008. Sejarah Nasional : Zaman Kuno, Balai Pustaka, Jakarta

Rahardjo, Supratikno. 2011. Peradaban Jawa: dari Mataram Kuno sampai Majapahit Akhir, Komunitas Bambu, Depok

Rajagopalachari. 2013, Kitab Epos Ramayana, IRCiSoD, Jogyakarta

Sedyawati, Edi. 2014. Kebudayaan di Nusantara, Komunitas Bambu, Depok

Soekmono. R. 1973. Pengantar Sejarah Kebudayaan Indonesia 2, Kanisius, Yogyakarta

Sutopo, H.B 2006, Metodologi Penelitian Kualitatif: Dasar Teori dan Terapannya dalam Penelitian, Universitas Sebelas Maret, Surakarta. 